\title{
Un nuevo marco legal para la evaluación
}

\section{New legal framework for the evaluation}

\author{
Mercedes Paja Fano \\ AEVAL-MINHFP \\ mercedes.paja@aeval.es
}

\begin{abstract}
RESUMEN
La íntima conexión existente entre transparencia y los procesos evaluativos se ha puesto de manifiesto, con mayor o menor desarrollo y alcance, en la normativa autonómica reguladora de la transparencia aprobada o en fase de proyecto. Se efectúa un recorrido por el panorama estatal y sobre todo, autonómico con el propósito de dar a conocer el tratamiento otorgado a la evaluación, que se inicia en planes y programas y culmina en políticas públicas, incluyendo en ocasiones participación ciudadana. Sea de uno u otro modo, la evaluación se constituye legalmente como una herramienta esencial para la rendición de cuentas.
\end{abstract}

\section{PALABRAS CLAVE}

Evaluación, participación ciudadana, políticas públicas, rendición de cuentas, transparencia.

\begin{abstract}
The close linkage between transparency and evaluation processes has been revealed, whit grater o lesser development and scope, by the regional transparency regulation adopted or remained in draft form. We examine the national scene and, specifically, regional government regulations for the purpose of making known the treatments associated with the evaluation. It starts with plans and programmes and concludes with public policies, sometimes including citizen participation. One way or another, evaluation legally has become an essential tool to ensure accountability.
\end{abstract}

\section{KEYWORDS}

Evaluation, citizen participation, public policies, accountability, transparency.

\section{SUMARIO}

INTRODUCCIÓN. 1. LA EVALUACIÓN DEL GRADO DE APLICACIÓN DE LAS DISPOSICIONES EN MATERIA DE TRANSPARENCIA. 2. EVALUACIONES DE PLANES, PROGRAMAS Y POLÍTICAS PÚBLICAS EN LAADMINISTRACIÓN GENERAL DEL ESTADO Y SU PUBLICIDAD ACTIVA. 3. EVALUACIONES DE PLANES, PROGRAMAS Y POLÍTICAS PÚBLICAS EN EL ÁMBITO AUTONÓMICO Y SU PUBLICIDAD ACTIVA. 3.1. Publicidad activa de las evaluaciones del grado de cumplimiento y resultados de planes y programas. 3.2. Participación ciudadana en la evaluación de políticas públicas. 3.3. Publicidad activa de las evaluaciones de políticas públicas y participación ciudadana. 3.3.1 Por un lado, se encuentran las comunidades autónomas del Principado de Asturias (proyecto), Illes Balears, País Vasco (proyecto) y la Comunidad Valenciana, que han aprovechado sus textos legales de transparencia para recoger la evaluación de las políticas públicas y su publicidad. 3.3.2. Dentro de este mismo apartado, el segundo grupo lo forman aquellas CC.AA con desarrollos específicos en materia de evaluación de políticas públicas, con independencia de las posibles referencias que, al respecto, pueda contener su normativa de transparencia: Castilla y León, Cataluña, Región de Murcia y Navarra. 


\section{INTRODUCCIÓN}

Nunca una materia ha suscitado tal consenso sobre la importancia de la evaluación como la que se ha puesto de manifiesto en la normativa reguladora en materia de transparencia que, en primer lugar y de modo general, recoge expresamente el mandato de evaluar su grado de aplicación. Así se contiene en la Ley 19/2013, de 9 de diciembre, de transparencia, acceso a la información pública y buen gobierno (LTAIBG), y en diez de las diecisiete regulaciones autonómicas aprobadas hasta la fecha o en fase de proyecto.

Pero la normativa de transparencia no se queda ahí en la necesidad de evaluar: cuando sujeta a publicidad activa los planes y programas anuales y plurianuales en los que se fijen objetivos concretos, así como las actividades, medios y tiempo previsto para su consecución, también ordena la evaluación de su grado de cumplimiento y resultados y su publicación periódica. Con esta exigencia la norma va más allá de su propio objeto.

Los términos del mandato evaluativo del grado de cumplimiento y resultados de los planes y programas de la normativa estatal se han replicado en la mayoría de la normativa autonómica, con alguna excepción muy puntual.

A partir de estos contenidos, algunas comunidades autónomas (CC.AA) han aprovechado la necesidad de regular esta materia para integrar en el contexto de la transparencia y rendición de cuentas la evaluación de la agenda política (Plan de Gobierno) o de las políticas públicas cuando aún no lo tuvieran previsto en otras disposiciones anteriores.

Mandato de evaluar y su publicidad que se eleva a rango legal y frecuentemente, viene acompañado del derecho de participación que se reconoce a los ciudadanos en el proceso de evaluación de políticas públicas y en todas sus fases: diseño, implementación, resultados e impacto.

De esta manera, la evaluación pasa a formar parte de la transparencia desde una triple dimensión, de menor a mayor:

- Una de carácter particular, circunscrito a la evaluación del grado de aplicación de la normativa reguladora en materia de transparencia.

- Un segundo estadio, constituido por la obligación legal de evaluar el grado de cumplimiento y resultados de los planes y programas (anuales u plurianuales) y su publicación.

- En tercer y último lugar, las regulaciones más avanzadas pasan a sujetar a publicidad activa la evaluación de las políticas públicas, no sólo las que se instrumentan en planes y programas.

$Y$ en casi todas las comunidades autónomas se reconoce el derecho de los ciudadanos a participar en los procesos evaluativos de políticas públicas.

La razón que ha podido motivar que la evaluación y en concreto, la evaluación de las políticas públicas, se incorpore a la transparencia con un mayor o menor alcance, desarrollo e intensidad, sin duda reside en la íntima conexión que existe entre ambas actividades, encaminadas a la mejora de la calidad democrática, al fomento de la participación ciudadana y a la rendición de cuentas y en definitiva, a recuperar la confianza de los ciudadanos, tal como se pone de manifiesto en las leyes o proyectos de ley del ámbito autonómico, con declaraciones del tipo de las que transcriben a continuación:

"En este sentido, el presente texto en particular busca instar al debate resolutivo en Euskadi sobre la mejora de la percepción de la ciudadanía respecto a la llamada cosa pública, su revalorización, contribuyendo a crear, en definitiva, una nueva cultura administrativa basada en los nuevos paradigmas que requieren los tiempos actuales, relacionados con los diversos aspectos de lo que se ha venido a llamar la buena gobernanza, abordada desde el triángulo conceptual que conforman la evaluación de políticas públicas, la transparencia y la participación de la ciudadanía en los asuntos públicos, partiendo de la premisa de que ninguno puede funcionar o sostenerse por sí solo, sin los otros dos.... La evaluación es necesaria para dar sentido a la transparencia, a la que dota de contenidos, y que de otra manera no sería sino un escaparate hueco.» (Exposición de motivos proyecto de ley de la Comunidad Autónoma del País Vasco).

«Principio de responsabilidad y rendición de cuentas: La actividad pública y la de sus servidores exige la asunción de la responsabilidad derivada de tal desempeño, mediante el impulso de la evaluación de políticas y la rendición de cuentas.» (Exposición de motivos proyecto de ley del Principado de Asturias). 
«Esta ley de transparencia pretende, en lo esencial, impulsar un modelo de gobernanza que avance hacia la modernización de la administración mediante criterios de gobierno abierto, corresponsable con la ciudadanía para dotarles de mayor protagonismo, mejorando el funcionamiento de los servicios públicos, optimizando el talento y la gestión del conocimiento de la propia administración, y contribuyendo, en definitiva, hacia un comportamiento ético y responsable en el Gobierno y la Administración, un ámbito que estará sujeto además a procesos continuos de evaluación.» (Art. 4, principios generales, de la Ley de la Comunidad Valenciana).

Esta artículo aborda, en primer lugar, cómo se ha plasmado la evaluación del grado de aplicación y cumplimiento de las propias normas de transparencia, así como el tratamiento de la evaluación de planes, programas y políticas públicas en el ámbito estatal, para pasar a presentar con un mayor detalle el alcance e importancia que las normas autonómicas conceden a la evaluación y su publicidad, teniendo en cuenta:

- Las normas autonómicas reguladoras de transparencia, aprobadas o en fase de proyecto a la fecha de cierre de este artículo ${ }^{1}$, a las que se otorga idéntica consideración.

- La restante normativa autonómica en vigor relacionada con la evaluación.

El recorrido que se realiza es marcadamente descriptivo, sin elementos valorativos más allá de las agrupaciones realizadas en los siguientes apartados, que atiende en exclusiva a los contenidos literales de las disposiciones estudiadas. En atención a su reciente aprobación (en la mayor parte de los casos y algunas, incluso, en fase de proyecto), su implementación se encuentra en fase embrionaria y no hace posible presentar resultados de su aplicación y muchos menos, efectuar un análisis bajo un criterio de eficacia. En general, la normativa autonómica que se cita carece de recorrido suficiente como para acometer, en este momento, un estudio en profundidad que permitiera arrojar conclusiones sobre los efectos producidos por el mandato legal de evaluar.

- La evaluación y su publicidad constituye un instrumento esencial para garantizar la transparencia y reforzar la rendición de cuentas.

- Las normativas autonómicas reguladoras de la transparencia han venido al fortalecer el panorama evaluativo existente a través de las numerosas referencias que, al respecto, recogen en su parte dispositiva.

- El escaso recorrido de la mayor parte de la normativa reguladora de la transparencia no hace posible presentar por el momento resultados sobre su mandato de evaluar ni un análisis bajo un criterio de eficacia.

\section{LA EVALUACIÓN DEL GRADO DE APLICACIÓN DE LAS DISPOSICIONES EN MATERIA DE TRANSPARENCIA}

Evaluar el grado de aplicación de las leyes de transparencia constituye un denominador común de casi todas las normativas reguladoras de la materia (estatal y autonómica).

«Casi» porque el término «evaluar» es sustituido en algunas de las normativas autonómicas por otros que conllevan una actividad de menor calado como «control» o «revisión».

Esta actividad evaluativa, o de control o de revisión del grado de aplicación y cumplimiento de la normativa reguladora de la transparencia se encomienda, en su mayoría, a un autoridad administrativa independiente ya existente o creada ad hoc.

La ley estatal, Ley 19/2013, de 9 de diciembre, de transparencia, acceso a la información pública y buen gobierno (LTAIBG) se refiere textualmente a la evaluación del grado de aplicación de esta Ley, función que atribuye al Consejo de Transparencia y Buen Gobierno (CTBG), autoridad administrativa independiente creada con la finalidad de promover la transparencia de la actividad pública, velar por el cumplimiento de las obligaciones de publicidad, salvaguardar el ejercicio de derecho de acceso a la información pública y garantizar la observancia de las disposiciones de buen gobierno.

\footnotetext{
1 La última consulta sobre el estado de tramitación de los proyectos de ley que se citan se realizó el 27 de marzo de 2017.
} 
Con el objeto de dar cumplimiento a esta función y tal como se recoge en su Memoria correspondiente al año $2015^{2}$, el CTBG ha suscrito un convenio con la Agencia de Evaluación de las Políticas Públicas y la Calidad de los Servicios (AEVAL) para la elaboración de una metodología de evaluación y seguimiento de la transparencia de las instituciones públicas.

Aunque esta fórmula evaluativa del grado de aplicación de la normativa reguladora de transparencia se ha replicado en la mayor parte de las normativas autonómicas, sin embargo, es pronto para determinar cuál es el significado que se otorga al término «evaluación» y si el proceso que se lleve a cabo en cumplimiento de esta obligación sea realmente evaluativo o quede reducido a un seguimiento, control o monitorización ${ }^{3}$, en la medida que el único criterio legal que se maneja es el de "cumplimiento», más próximo a un sistema de seguimiento que a un sistema de evaluación, en el que entran en juego otros criterios de valor como cobertura, pertinencia, coherencia, eficacia y calidad (técnica y democrática), equidad,

- La transparencia no deja de ser una política pública que se formaliza a través de una Ley y por lo tanto debería evaluarse su diseño, implantación, resultados e impactos.

En el cuadro que se recoge a continuación se muestran las distintas fórmulas utilizadas en los textos legales reguladores de la transparencia, con excepción de dos comunidades autónomas cuya normativa en esta materia es anterior a la $\mathrm{LTAIBG}^{4}$, y no contienen previsión alguna al respecto ni han sido objeto de adaptación:

1. ${ }^{a} \quad$ La más antigua es la Ley $4 / 2011$, de 31 de marzo, de buena administración y de buen gobierno de las Illes Balears, que no sigue en su contenido ni en su estructura el modelo fijado por la LTAIBG en $2013^{5}$

2. ${ }^{a} \quad$ otra norma del mismo año que la LTAIBG, pero anterior, es la Ley 4/2013, de 21 de mayo, de Gobierno Abierto de Extremadura, que tampoco contempla la evaluación o control de su grado de aplicación 6 .

CUADRO 1. TIPO DE ACTIVIDAD PARA VERIFICAR EL GRADO DE CUMPLIMIENTO DE LA NORMATIVA DE TRANSPARENCIA Y ÓRGANO COMPETENTE. NIVEL AUTONÓMICO

\begin{tabular}{lll}
\hline $\begin{array}{l}\text { Comunidad } \\
\text { autonoma }\end{array}$ & $\begin{array}{l}\text { Tipo de actividad para verificar } \\
\text { cumplimiento regulación } \\
\text { transparencia }\end{array}$ & Órgano competente \\
\hline ANDALUCIA & Control del cumplimiento de la ley & $\begin{array}{l}\text { Consejo de la Transparencia y Protección } \\
\text { de Datos de Andalucía }\end{array}$ \\
\hline ARAGÓN & $\begin{array}{l}\text { Evaluación del grado de aplicación y } \\
\text { cumplimiento de las obligaciones de } \\
\text { transparencia }\end{array}$ & Consejo de Transparencia de Aragón \\
\hline PRINCIPADO DE & $\begin{array}{l}\text { Evaluación del grado de cumplimiento } \\
\text { de la ley }\end{array}$ & $\begin{array}{l}\text { Comisión de Transparencia del Principado } \\
\text { de Asturias }\end{array}$ \\
\hline
\end{tabular}

2 La Memoria anual 2015 del CTBG se encuentra disponible en su página web http://www.consejodetransparencia.es/ct_Home/ plan_memoria/memorias.html. Un resumen de la misma ha sido objeto de publicación en Boletín Oficial del Estado (BOE) de 28 de diciembre.

3 Algunas CC.AA han desarrollado esta previsión legal. Por ejemplo, Canarias, mediante Orden de 10 de junio de 2016 , por la que se determina el contenido del informe sobre el grado de aplicación de la Ley 12/2014, de 26 de diciembre, de transparencia y acceso a la información pública.

4 La normativa de la Comunidad Foral de Navarra también es anterior a la LTAIBG (del año 2012); sin embargo, ha sido objeto de modificación, entre otros objetivos, para crear un órgano específico e independiente en materia de transparencia. Por otro lado, Galicia contaba con una norma anterior -Ley 4/2006, de 30 de junio- que ha sido derogada por otra ley aprobada en 2016 objeto de este análisis.

5 Sin embargo, como se verá más adelante, sus previsiones la sitúan entre la normativa más avanzada en materia de evaluación. Cuenta con una Dirección General de Participación y Transparencia (dentro de la Consejería de Transparencia, Cultura y Deportes) con competencias en materia de coordinación interdepartamental de medidas para impulsar la transparencia y el buen gobierno en la Administración.

6 En esta Comunidad Autónoma, se atribuyen a la Consejería de Hacienda y Administración Pública competencias en materia de inspección de servicios, evaluación y calidad de la Administración. 


\begin{tabular}{|c|c|c|}
\hline $\begin{array}{l}\text { Comunidad } \\
\text { autonoma }\end{array}$ & $\begin{array}{l}\text { Tipo de actividad para verificar } \\
\text { cumplimiento regulación } \\
\text { transparencia }\end{array}$ & Órgano competente \\
\hline CANARIAS & $\begin{array}{l}\text { Evaluación del grado de aplicación } \\
\text { y cumplimiento de la ley }\end{array}$ & $\begin{array}{l}\text { Comisionado de Transparencia y Acceso } \\
\text { a la Información Pública }\end{array}$ \\
\hline CANTABRIA (proyecto) & $\begin{array}{l}\text { Revisión el grado de cumplimiento } \\
\text { de la ley }\end{array}$ & Comisión de Transparencia y Participación \\
\hline CASTILLA-LA MANCHA & $\begin{array}{l}\text { Evaluación del grado de aplicación } \\
\text { y cumplimiento de la ley }\end{array}$ & $\begin{array}{l}\text { Consejo Regional de Transparencia } \\
\text { y Buen Gobierno }\end{array}$ \\
\hline CASTILLA Y LEÓN & $\begin{array}{l}\text { Evaluación del grado de aplicación } \\
\text { de la ley }\end{array}$ & $\begin{array}{l}\text { Comisionado de Transparencia } \\
\text { (Procurador de lo Común) }\end{array}$ \\
\hline CATALUÑA & Evaluación de la aplicación de la ley & Sindic de Greuges \\
\hline GALICIA & $\begin{array}{l}\text { Control del cumplimiento de las } \\
\text { obligaciones de transparencia }\end{array}$ & $\begin{array}{l}\text { Comisionado de la Transparencia } \\
\text { (Valedor del Pueblo) }\end{array}$ \\
\hline LA RIOJA & $\begin{array}{l}\text { Control del cumplimiento de las } \\
\text { obligaciones derivadas de la ley }\end{array}$ & $\begin{array}{l}\text { Consejería competente en materia } \\
\text { de Administración Pública }\end{array}$ \\
\hline MADRID (proyecto) & $\begin{array}{l}\text { Velar por el cumplimiento de las } \\
\text { obligaciones prevsita en la ley }\end{array}$ & $\begin{array}{l}\text { Consejería competente en materia } \\
\text { de calidad de los servicios y atención } \\
\text { al ciudadadan }\end{array}$ \\
\hline REGIÓN DE MURCIA & $\begin{array}{l}\text { Evaluación del grado de aplicación } \\
\text { y cumplimiento de las obligaciones } \\
\text { en materia de transparencia }\end{array}$ & $\begin{array}{l}\text { Consejo de la Transparencia de la Región } \\
\text { de Murcia }\end{array}$ \\
\hline NAVARRA & $\begin{array}{l}\text { Evaluación del grado de aplicación } \\
\text { y cumplimiento de las obligaciones } \\
\text { en materia de transparencia }\end{array}$ & Consejo de Transparencia de Navarra \\
\hline PAÍS VASCO (proyecto) & $\begin{array}{l}\text { Evaluación del grado de aplicación } \\
\text { de la ley en materia de transparencia } \\
\text { y acceso a la información pública }\end{array}$ & $\begin{array}{l}\text { Agencia Vasca de Transparencia } \\
\text {-Gardena- }\end{array}$ \\
\hline COMUNIDAD VALENCIANA & $\begin{array}{l}\text { Evaluación del grado de aplicación } \\
\text { y cumplimiento de la ley }\end{array}$ & $\begin{array}{l}\text { Consejo de Transparencia, Acceso } \\
\text { a la Información Pública y Buen Gobierno }\end{array}$ \\
\hline
\end{tabular}

Fuente: elaboración propia a partir de la normativa autonómica reguladora de la transparencia (en vigor o en fase de proyecto).

Nota: figuran en cursiva las comunidades autónomas con normas de transparencia en fase de proyecto (Principado de Asturias, Cantabria, Madrid y País Vasco) a la fecha de cierre de este documento. No se incluye Illes Balears ni Extremadura por disponer de textos aprobados con anterioridad a la LTAIBG y no adaptados en este concreto contenido, que no contemplan.

\section{EVALUACIONES DEPLANES,PROGRAMASYPOLÍTICAS PÚBLICASEN LAADMINISTRACIÓN GENERAL DEL ESTADO Y SU PUBLICIDAD ACTIVA}

Cuando la LTAIBG sujeta a publicidad activa un conjunto de información, en el bloque destinado a la información institucional, organizativa y de planificación, dispone lo siguiente:

"Las Administraciones Públicas publicarán los planes y programas anuales y plurianuales en los que se fijen objetivos concretos, así como las actividades, medios y tiempo previsto para su consecución. Su grado de cumplimiento y resultados deberán ser objeto de evaluación y publicación periódica junto con los indicadores de medida y valoración, en la forma en que se determine por cada Administración competente.

En el ámbito de la Administración General del Estado (AGE) corresponde a las inspecciones generales de servicios la evaluación del cumplimiento de estos planes y programas» (art. 6.2 LTAIBG). 
De acuerdo con la Disposición final octava, «Título competencial»:

"La presente Ley se dicta al amparo de lo dispuesto en los artículos 149.1.1. ${ }^{a}, 149.1 .13 .^{a}$ y 149.1.18. ${ }^{a}$ de la Constitución. Se exceptúa lo dispuesto en el segundo párrafo del apartado 2 del artículo 6, el artículo 9, los apartados 1 y 2 del artículo 10, el artículo 11, el apartado 2 del artículo 21, el apartado 1 del artículo 25, el título III y la disposición adicional segunda».

Por consiguiente, la sujeción a publicidad activa de los planes y programas y su evaluación constituye normativa básica; no así la determinación de la unidad encargada de evaluar, que en el ámbito de la Administración General del Estado se atribuye a las inspecciones de servicios. Hay que esperar para comprobar cómo se despliega este mandato evaluativo a cargo de estas unidades, con un perfil más enfocado a la evaluación de la calidad de los servicios que a la evaluación de planes y programas. Su normativa reguladora $^{7}$ expresamente señala que se constituyen como órganos especializados en el control interno y en la evaluación de la eficacia y calidad de los servicios prestados, el seguimiento de los objetivos asignados a las distintas unidades administrativas y la modernización de estructuras y mejora de procedimientos, tanto de los propios departamentos como de sus organismos públicos dependientes.

En este nivel de gobierno, el mandato de evaluar los planes y programas y su publicidad se completa con las funciones atribuidas en materia de evaluación de políticas públicas a la AEVAL por su Estatuto, aprobado por Real Decreto 1418/2006, de 1 de diciembre (y vigente en tanto concluya el plazo de adaptación de las agencias existentes en el sector público a lo dispuesto en la Ley 40/2015, de 2 de octubre, de Régimen Jurídico del Sector Público). Estatuto que no recoge expresamente el principio de publicidad de las evaluaciones de políticas públicas, que se entiende implícito en lo dispuesto en la letra b) de su artículo 7, cuando somete toda su actuación a los principios de transparencia y participación ciudadana.

De modo particular, se ha aprobado normas que encomiendan evaluaciones de determinadas intervenciones públicas a la AEVAL y ordenan expresamente su publicación (por ejemplo, la Ley 20/2013, de 19 de diciembre, de garantía de la unidad de mercado, Disposición adicional sexta $\left.{ }^{8}\right)$.

\section{EVALUACIONES DE PLANES, PROGRAMAS Y POLÍTICAS PÚBLICAS EN EL ÁMBITO AUTONÓMICO Y SU PUBLICIDAD ACTIVA}

Un análisis de la normativa autonómica permite establecer diferentes grupos en materia de evaluación y su publicidad activa, en función del menor o mayor alcance del objeto de evaluación (planes y programas y en un estadio más avanzado, políticas públicas) y la participación ciudadana en los procesos evaluativos.

\subsection{Publicidad activa de las evaluaciones del grado de cumplimiento y resultados de planes y programas}

La normativa autonómica reguladora de la transparencia ha recogido el mandato de sujetar a publicidad activa los planes y programas, así como su evaluación ${ }^{9}$, bien transcribiendo la norma básica, bien con una remisión expresa a la misma.

En este primer grupo, la evaluación se ciñe a los planes y programas y su publicidad, e incluyen alguna referencia a la evaluación de políticas públicas o a una posible participación ciudadana en asuntos públicos, pero de modo genérico y sin un desarrollo posterior en la norma de transparencia o en otras disposiciones en vigor. Se trata de las comunidades autónomas de Andalucía, Galicia y La Rioja ${ }^{10}$.

\footnotetext{
7 Real Decreto 799/2005, de 1 de julio, por el que se regulan las inspecciones generales de servicios de los departamentos ministeriales.

${ }^{8}$ Disposición adicional sexta de la Ley 20/2013: Evaluación anual de la Agencia Estatal de Evaluación de las Políticas Públicas y la Calidad de los Servicios. "La Agencia Estatal de Evaluación de las Políticas Públicas y la Calidad de los Servicios elaborará una evaluación anual sobre la implementación y los principales efectos en ámbitos de actuación pública concretos, de las medidas contempladas en esta Ley. Esta evaluación se remitirá a la Comisión Delegada del Gobierno para Asuntos Económicos y a las Comisiones de Economía y Competitividad del Congreso de los Diputados y del Senado, tras lo cual se hará pública».

9 Con excepción de la Comunidad Autónoma de la Región de Murcia, que no utiliza el término «evaluación», cuando sujetan a publicidad activa el grado de cumplimiento y resultados de los planes y programas. Pese a ello y en atención a otros contenidos y normativa, se ha considerado una CA que se sitúa entre las más avanzadas en materia evaluativa y su publicidad en el sentido que se expone en los epígrafes siguientes.

10 Estas tres CC.AA coinciden, además, en haber sustituido el término «evaluar» por el del «control» a la hora de verificar el grado de aplicación de su respectiva ley de transparencia.
} 


\section{Andalucía}

La Comunidad Autónoma de Andalucía destaca sobre las otras dos de su grupo, comenzando porque en la exposición de motivos de su Ley 1/2014, de 24 de junio, de transparencia pública, cita por dos veces la evaluación de políticas públicas vinculada a dos preceptos de su Estatuto de Autonomía. Por un lado, trae a colación el artículo $10.1^{11}$, como justificación de la necesidad de fomentar la participación ciudadana en la elaboración, prestación y evaluación de políticas públicas. De otra parte, vincula la evaluación de políticas públicas al artículo 138 del citado Estatuto de Autonomía ${ }^{12}$ al que se refiere como fundamento en la búsqueda de una mayor transparencia y con el objetivo de avanzar en el diseño de un sistema andaluz de evaluación de políticas públicas. Sin embargo, ambas declaraciones de la parte expositiva de su norma de transparencia no acaban de desarrollarse en su parte dispositiva ${ }^{13}$, en la que se limita a la evaluación de los planes y programas y su publicidad activa. Pero da un paso importante al definir, a estos efectos, la evaluación de políticas públicas, en su artículo 12, denominado «Información sobre planificación y evaluación»:

«...proceso sistemático de generación de conocimiento encaminado a la comprensión integral de una intervención pública para alcanzar un juicio valorativo basado en evidencias respecto de su diseño, puesta en práctica, resultados e impactos. Su finalidad es contribuir a la mejora de las intervenciones públicas e impulsar la transparencia y la rendición de cuentas».

Es de destacar que la norma contenga una definición de lo que se debe entender por evaluación ${ }^{14}$, en la medida que neutraliza cualquier posibilidad de que el proceso que se llegue a realizar no se trate realmente de una evaluación en sentido estricto. Definición legal que, por otra parte, coincide con la que se viene propugnando desde la AEVAL: una definición casi idéntica se puede encontrar en el documento "Fundamentos de evaluación de políticas públicas"15 (AEVAL, 2010).

\section{Galicia}

Esta Comunidad Autónoma, en su vigente Ley 1/2016, de 28 de enero, de transparencia y buen gobierno ${ }^{16}$ se remite expresamente a la normativa básica (LTAIBG) en lo que respecta a la información que ha de ser objeto de publicidad activa y añade que también estarán sujetas a publicidad activa las evaluaciones de calidad, proceso distinto de las evaluaciones de políticas públicas.

La norma recoge la participación ciudadana en los asuntos públicos como uno de sus principios, pero de un modo genérico, sin desarrollo y sin mención expresa a la evaluación de políticas públicas.

Tampoco se encuentran más previsiones evaluativas en la Ley $1 / 2015$, de 1 de abril, de garantía de la calidad de los servicios públicos y de la buena administración. En su parte expositiva declara que se pasa a integrar el procedimiento de evaluación con participación ciudadana en el ciclo de políticas públicas, pero lo cierto es que tal declaración carece de tratamiento en su articulado que, en su mayor parte, se dedica a la evaluación de la calidad de los servicios públicos, en coherencia con el título de la norma. Únicamente en uno de los preceptos se cita la evaluación de las políticas públicas aunque en unos términos algo confusos, por su constante remisión a la calidad de los servicios públicos ${ }^{17}$.

11 Artículo 10.1 del Estatuto de Autonomía de Andalucía: «La Comunidad Autónoma de Andalucía promoverá las condiciones para que la libertad y la igualdad del individuo y de los grupos en que se integra sean reales y efectivas; removerá los obstáculos que impidan o dificulten su plenitud y fomentará la calidad de la democracia facilitando la participación de todos los andaluces en la vida política, económica, cultural y social».

12 Artículo 138 del Estatuto de Autonomía de Andalucía: Evaluación de políticas públicas: «La ley regulará la organización y funcionamiento de un sistema de evaluación de las políticas públicas».

13 Se encuentra en trámite un proyecto de ley de participación ciudadana de Andalucía que contiene un capítulo específico dedicado a la participación ciudadana en la evaluación de las políticas públicas de la Junta de Andalucía.

14 La normativa andaluza de transparencia no es la única en esta materia que recoge una definición de «evaluación», como se expone más adelante.

15 «En líneas generales se entiende por evaluación un proceso integral de observación, medida, análisis e interpretación, encaminado al conocimiento de una intervención pública -norma, programa, plan o política-, que permite alcanzar un juicio valorativo basado en evidencias respecto a su diseño, puesta en práctica, resultados e impactos.» (AEVAL, 2010; 13).

16 Esta norma deroga la anterior Ley 4/2006, de 30 de junio, de transparencia y de buenas prácticas en la Administración pública gallega.

17 Art. 23.1 de la Ley 1/2015, de 1 de abril «La Xunta de Galicia evaluará la calidad de las políticas públicas que se diseñen y los servicios públicos prestados con la finalidad de obtener información objetiva y sistemática, identificar áreas de mejora y planificar e implementar iniciativas para mejorar la calidad de los servicios públicos autonómicos». 


\section{La Rioja}

Este primer grupo se cierra con la Comunidad Autónoma de La Rioja que con la Ley 3/2014, de 11 de septiembre, de transparencia y buen gobierno, reproduce las obligaciones de publicidad activa de la normativa básica. Y aun cuando dedica uno de sus capítulos al derecho de participación ciudadana en los asuntos públicos, parece recoger las bases para su impulso y posterior desarrollo.

- El conjunto de normas autonómicas reguladoras de la transparencia contemplan, como mínimo, la evaluación del grado de cumplimiento y resultados de los planes y programas y su publicación, siguiendo el mandato de la normativa básica (LTAIBG)

- Asimismo, y aun cuando quede en una mera declaración que requiere de desarrollo, como mínimo reconocen el derecho de los ciudadanos a participar en los asuntos públicos o en el ciclo de políticas públicas

\subsection{Participación ciudadana en la evaluación de políticas públicas}

Con un mayor alcance en lo que se refiere a la evaluación se posicionan las restantes CC.AA, que cuentan con regulaciones de transparencia, aprobadas o en fase de proyecto, $u$ otras disposiciones en vigor que desarrollan y complementan el panorama desde la perspectiva de la evaluación de las políticas públicas.

Aunque la casuística puede ser ciertamente variada, en este segundo grupo se recoge un conjunto de CC.AA que no obstante acotar en algunos casos la evaluación (y su publicidad) al grado de cumplimiento y resultados de los planes y programas, dan un paso adelante al reconocer de modo explícito el derecho de la ciudadanía a participar en la evaluación de las políticas públicas ${ }^{18}$ como una manifestación del gobierno abierto. Este grupo está formado por las comunidades autónomas de Aragón, Cantabria (proyecto), Canarias, Castilla-La Mancha, Extremadura y Madrid (proyecto); destacando las dos primeras comunidades autónomas sobre las restantes.

\section{Aragón}

La Comunidad Autónoma de Aragón -con su Ley 8/2015, de 25 de marzo, de transparencia de la actividad pública y participación ciudadana ${ }^{19}$ - se posiciona en una situación de supremacía en este grupo, ya que son numerosas las referencias a la evaluación a lo largo de su articulado, comenzando por declarar que constituye uno de sus objetos garantizar de forma efectiva el «derecho de participación en la planificación, elaboración y evaluación de las políticas públicas del Gobierno de Aragón».

Parece apostar firmemente por la evaluación de las políticas públicas y en este sentido, menciona como uno de los principios que deben informar la aplicación de la ley el de responsabilidad y rendición de cuentas a través de la promoción de la cultura de la evaluación.

Recoge, asimismo, una definición de «evaluación» en parecidos términos que Andalucía:

«...proceso integral de observación, análisis y consideración de la intervención pública, encaminada a valorar su diseño, desarrollo y ejecución, el cumplimiento de sus objetivos, su impacto y las correcciones necesarias para la mejora de las estrategias públicas».

En materia de publicidad activa, y junto a la evaluación de los planes y programas anuales y plurianuales, prevé la evaluación de un Plan de Gobierno ${ }^{20}$ que debe aprobar el Gobierno de Aragón para

18 Derecho más amplio que la participación ciudadana en el proceso de elaboración de disposiciones que emanan del Poder Ejecutivo, reforzado con la entrada en vigor, el 2 de octubre de 2016, de la Ley 39/2015, de 1 de octubre de Procedimiento Administrativo Común de las Administraciones Públicas, que en su artículo 133 establece una fase de consulta pública que debe preceder a la elaboración de los proyectos o anteproyectos de ley o de reglamento. Este mandato, de obligado cumplimiento para todas las Administraciones Públicas (AA.PP), ha sido objeto de desarrollo a nivel AGE con la Orden PRE/1590/2016, de 3 de octubre (operativo en 9 meses).

19 Esta ley se complementa y desarrolla con otra que actualmente se encuentra en fase de proyecto: proyecto de ley de integridad ética y pública.

${ }^{20}$ Estos planes de Gobierno (que se recogen en los textos de las CC.AA de Aragón, Madrid o el País Vasco) difieren por su mayor contenido y alcance del Plan (Anual) Normativo que se contempla en el artículo 132 de la citada Ley 39/2015, de 1 de octubre, de Procedimiento Administrativo Común de las Administraciones Públicas según el cual, con carácter anual, las AA.PP publicarán en el 
cada legislatura, con contenido abierto y en el que se identificarán, entre otros extremos, los objetivos estratégicos perseguidos, las actividades y medios necesarios para alcanzarlos, así como los indicadores que permitirán su seguimiento y la evaluación. Ordena la presentación de un informe de las principales actuaciones realizadas en un plazo no superior a cuatro meses desde la finalización de cada ejercicio presupuestario.

Dedica un título de la ley (Título III) a la participación ciudadana en la planificación, elaboración, ejecución y evaluación de las políticas públicas del Gobierno de Aragón, así como la participación en los ámbitos político, cultural, económico y social de la Comunidad Autónoma. Para su consecución, establece la elaboración de un Programa Anual de Participación Ciudadana como documento estratégico que contenga los proyectos normativos, planes y programas que serán objeto de procesos y mecanismos de participación. Instrumentos de participación ciudadana que serán objeto de evaluación anual con el fin de implementar los procesos de mejora que, en su caso, correspondan.

\section{Canarias}

Con menor énfasis en la evaluación, la Comunidad Autónoma de Canarias en su Ley 12/2014, 26 de diciembre, de transparencia y de acceso a la información pública, se ciñe a la normativa básica al indicar que será objeto de publicidad activa la evaluación de los resultados de los planes y programas.

Aunque sus previsiones relacionadas con la evaluación son más modestas, se incluye bajo este apartado en la medida que la ley canaria de transparencia se complementa con otra anterior: la Ley 5/2010, de 21 de junio, canaria de fomento de la participación ciudadana, que persigue como uno de sus fines establecer mecanismos de evaluación de las políticas públicas y de investigación del estado de la opinión pública por parte de la ciudadanía. Desarrolla en su articulado un conjunto de instrumentos de participación ciudadana en la elaboración y evaluación de políticas públicas y dispone las evaluaciones de estos procesos participativos.

\section{Cantabria}

La Comunidad Autónoma de Cantabria, en su proyecto de ley de transparencia de la actividad pública y participación ciudadana, también conecta la evaluación de las políticas públicas al derecho constitucional de los ciudadanos a participar en los asuntos públicos, y al principio de responsabilidad y rendición de cuentas, uno de los principios generales de la transparencia.

Recoge una definición de evaluación en idénticos términos que Aragón:

«proceso integral de observación, análisis y consideración de la intervención pública, encaminado a valorar su diseño, desarrollo y ejecución, el cumplimiento de los objetivos, su impacto y las correcciones necesarias para la mejora de las estrategias públicas».

En materia de publicidad activa, y junto a la evaluación del grado de cumplimiento y resultados de los planes y programas, contempla la publicidad de la «información sobre los resultados de las evaluaciones de calidad y de la incidencia social de las políticas públicas» ${ }^{21}$. Pero no acaba de concretar que se entiende por «incidencia social». Todo parece apuntar a que esta expresión se encuentra en íntima conexión con el derecho que se reconoce a la ciudadanía a participar en la evaluación de políticas y calidad de los servicios públicos y que regula en su Título III. En tal sentido, obliga a las administraciones públicas de Cantabria al fomento de la participación individual o colectiva especialmente en los asuntos públicos referidos a la evaluación de las políticas públicas, y dispone que cada evaluación de las políticas públicas llevará asociada una acción de escucha de la ciudadanía. Desarrolla los instrumentos de participación ciudadana, y establece su evaluación anual con el fin de implementar los procesos de mejora que, en su caso, correspondan.

\footnotetext{
correspondiente Portal de la Transparencia un Plan que contendrá las iniciativas legislativas o reglamentarias que vayan a ser elevadas para su aprobación en el año siguiente. Para la AGE, los artículos 25 y 28 de la Ley de Gobierno en la nueva redacción dada por la Ley 40/2015, disponen que se publicará en el Portal un Plan Anual Normativo y un Informe anual de evaluación del grado de cumplimiento del Plan Anual Normativo.

21 En idénticos términos se recoge en los textos normativos de las Comunidades Autónomas de Cataluña y Navarra: sujeción a publicidad activa de los resultados de las evaluaciones de calidad y de la incidencia social de las políticas públicas.
} 


\section{Castilla-La Mancha}

La Comunidad Autónoma de Castilla-La Mancha incluye en su norma -Ley 4/2016, de 15 de diciembre, de transparencia y buen gobierno- la misma definición de evaluación que Aragón y Cantabria:

«proceso integral de observación, análisis y consideración de la intervención pública, encaminado a valorar su diseño, desarrollo y ejecución, el cumplimiento de los objetivos, su impacto y las correcciones necesarias para la mejora de las estrategias públicas».

Con un mayor detalle que la normativa básica, sujeta a publicidad los planes y programas anuales y plurianuales de carácter general o sectorial que establezcan las directrices estratégicas de las políticas públicas, y añade los "criterios, los indicadores y la metodología para evaluar su cumplimiento, las cuantías asignadas a incentivos o productividad por el cumplimiento, así como el resultado de su evaluación, una vez ejecutados». Resulta significativo que este precepto (artículo 11) se denomine «información sobre planificación y evaluación».

Dentro del título dedicado al buen gobierno, destina un capítulo al Gobierno abierto, entendido como aquel que busca e incentiva la participación y colaboración ciudadana en la planificación, diseño y evaluación de las políticas públicas más relevantes, de carácter general y sectorial (caracterización de «más relevantes» que luego no se vuelve a citar en el texto cuando se refiere a la evaluación de las políticas públicas). Todo apunta a que esta previsión legal de participación ciudadana parece requerir de una posterior concreción (legal o reglamentaria), como ya se advierte en la exposición de motivos de la ley.

También deja enunciado como uno de los principios que informan la buena Administración el de la evaluación permanente, a través de indicadores objetivos, de la gestión administrativa y los procesos de participación.

Con anterioridad, esta Comunidad Autónoma ha suscrito convenios de colaboración con la AEVAL para la realización de evaluaciones de algunas intervenciones públicas, como la "Evaluación de los Programas de Selección y Formación de la Escuela de Administración Regional de Castilla-La Mancha" (AEVAL, 2011).

\section{Extremadura}

La Comunidad Autónoma de Extremadura, con su Ley 4/2013, de 21 de mayo, de Gobierno abierto, al igual que los restantes textos legales, y pese a ser anterior a la LTAIBG, somete a publicidad activa planes y programas anuales y plurianuales y las evaluaciones periódicas de sus resultados y grado de cumplimiento, siguiendo la normativa básica.

Se incluye en este grupo porque en el título dedicado a la participación y colaboración ciudadana (Título III) expresamente reconoce el derecho de la ciudadanía a participar en la evaluación de políticas y calidad de los servicios públicos: junto al proceso participativo y de consulta de los proyectos de ley, establece que cada evaluación de las políticas públicas llevará asociada una acción de escucha de la ciudadanía. Pero no contempla expresamente la evaluación de los mecanismos de participación.

Es positivo que se reconozca el derecho de los ciudadanos a participar en los asuntos públicos, pero las previsiones de esta norma en relación con la evaluación de las políticas públicas se quedan ahí. Por tanto, y al igual que Canarias, constituyen ejemplos de regulaciones más limitadas que las restantes de su grupo desde un punto de vista evaluativo.

\section{Madrid}

También y políticas públicas, como el derecho a que se haga público el resultado definitivo del procedimiento en el que haya participado. Pero sin mención a la evaluación de los instrumentos de participación ciudadana.

- La mayoría de las comunidades autónomas reconocen legalmente el derecho de la ciudadanía a participar en el diseño, elaboración y evaluación de las políticas públicas. E incluso ordenan la evaluación de los instrumentos de participación y del grado de participación. Participación y transparencia como pilares fundamentales del gobierno abierto. 
- El informe de la Organización para la Cooperación y el Desarrollo Económico (OCDE) "Panorama de las Administraciones Públicas 2015" pone el acento en este impulso de la participación ciudadana, como un instrumento para aumentar la confianza en las instituciones públicas y que demanda inexcusablemente el acceso a la información. Bajo el título "Los procesos de formulación de políticas integradoras" destaca la importancia de dar acceso a todos los segmentos de la sociedad en la toma de decisiones públicas "con el fin de reflejar mejor sus necesidades y aspiraciones, tanto en la formulación de políticas como en la prestación de servicios...» Y, además, "hacer que los ciudadanos participen de forma activa en el diseño y ejecución de las políticas públicas también podría aumentar su legitimidad y eficacia, y fomentar el sentimiento de pertenencia de los ciudadanos».

\subsection{Publicidad activa de las evaluaciones de políticas públicas y participación ciudadana}

Bajo este último apartado se incluyen las restantes comunidades autónomas, que expresamente ordenan la evaluación de sus políticas públicas y su publicidad, bien en su normativa reguladora de la transparencia, bien en otras disposiciones normativas.

En este grupo, la evaluación transciende de los planes y programas para alcanzar al conjunto de las políticas públicas ${ }^{22}$, con independencia del instrumento utilizado (planes, programas, proyectos, leyes,...).

\subsubsection{Por un lado, se encuentran las comunidades autónomas del Principado de Asturias (proyecto), Illes Balears, País Vasco (proyecto) y la Comunidad Valenciana, que han aprovechado sus textos legales de transparencia para recoger la evaluación de las políticas públicas y su publicidad}

\section{Principado de Asturias}

El proyecto de ley de transparencia de la Comunidad Autónoma del Principado de Asturias considera la evaluación de políticas públicas como un instrumento de rendición de cuentas, mandata su publicidad y la desarrolla en un capítulo específico. Son múltiples las referencias que contiene al respecto, comenzando por el preámbulo del proyecto en el que declara que su pretensión es impulsar un modelo de gobernanza "...contribuyendo, en definitiva, hacia un comportamiento ético y responsable en el Gobierno y la Administración, un ámbito que estará sujeto además a procesos continuos de evaluación».

En coherencia con esta declaración de principios, dedica un título (Título IV), a la evaluación de políticas públicas, que considera

«... un instrumento de rendición de cuentas para la mejora continua de la transparencia, calidad, pertinencia y eficacia de las Administraciones públicas asturianas. Todo ello con la finalidad de contribuir a un mayor conocimiento, confianza y participación de la ciudadanía en dichas políticas públicas».

Dispone que la evaluación será de aplicación a todo el conjunto de políticas, estén o no articuladas en planes, programas o documentos estratégicos similares. $Y$ todas estas evaluaciones quedan sujetas al principio de publicidad activa, viniendo obligadas las Administraciones públicas asturianas a difundir sus resultados a través de la página web corporativa, y facilitando a la ciudadanía el acceso a este tipo de información dentro de los límites que establece esta ley.

En este título ya comienza a referirse a la participación ciudadana en las evaluaciones, que pasa a regular en el título siguiente (Título V). Participación ciudadana que extiende de forma obligatoria a programas y planes; y potestativamente, a cualquier otra iniciativa de actuación. Sin embargo, no prevé expresamente la evaluación de los instrumentos de participación.

22 Concepto de políticas públicas que se puede definir como «el conjunto de objetivos, decisiones y acciones que lleva a cabo un gobierno para solucionar los problemas que en un momento determinado los ciudadanos y el propio gobierno consideran prioritarios» (TAMAYO SÁEZ, M., 1997). 
El Principado de Asturias constituye otro ejemplo de Comunidad Autónoma que ha participado con la AEVAL en procesos evaluativos; en concreto, en la "Evaluación de la Estrategia de Cuidados Paliativos del Sistema Nacional de la Salud" (AEVAL, 2010).

\section{Illes Balears}

Por su parte, la Comunidad Autónoma de las Illes Balears, con su Ley 4/2011, de 31 de marzo, de buena administración y de buen gobierno, muy anterior a las actuales regulaciones de transparencia, se posiciona en este grupo más avanzado por las numerosas referencias a la evaluación de las políticas públicas y su publicidad, tanto en su exposición de motivos como en su parte dispositiva.

Entre los principios que informan la buena administración y el buen gobierno cita la responsabilidad y rendición de cuentas, a través de la promoción de las evaluaciones y reconoce la participación ciudadana en la evaluación de políticas públicas, aunque no contempla la evaluación de los procesos participativos que quedan enunciados con escaso desarrollo.

Por el contrario, dedica especial atención a fijar las bases de un sistema de evaluación de políticas públicas que define de forma similar a las restantes comunidades autónomas:

«...proceso sistémico de observación, análisis e interpretación de una intervención pública de cualquier tipo -plan, programa, proyecto u otra acción-, para obtener un juicio valorativo de su diseño, funcionamiento, resultados y efectos, basado en evidencias».

También señala que su finalidad es ser útil a la sociedad, como instrumento de mejora de la calidad y la eficacia de los servicios públicos, la eficacia del sector público y perfeccionar la calidad democrática. Enuncia una lista abierta los criterios que deben seguir este sistema, el alcance de su aplicación, las modalidades y los contenidos. Y dispone la obligatoriedad de su registro y publicación como mínimo en la página web de la Administración de la Comunidad Autónoma de las Illes Balears.

Por último, crea una la Oficina de Evaluación Pública de las Illes Balears como órgano de ejecución, de coordinación y de consulta de las acciones de evaluación de políticas, planes y programas, organizaciones y servicios públicos de las instituciones públicas y entes instrumentales de las Illes Balears.

Pese al tiempo transcurrido desde su aprobación, no hay constancia de la implementación de esta norma en lo referente a la evaluación de políticas públicas. No obstante, esta Comunidad Autónoma ha suscrito convenios marco con la AEVAL para la realización de evaluaciones de algunas de sus intervenciones públicas como, por ejemplo la "Evaluación del Plan de Calidad de Recursos Humanos de los Servicios Generales de la Administración de la CAIB" (AEVAL, 2015). Actualmente, se encuentra en vigor el Convenio marco de colaboración suscrito el 2 de agosto de 2016 entre la AEVAL y la Consejería de Transparencia, Cultura y Deportes de la Comunidad Autónoma de las Illes Balears, para la colaboración en el ámbito de la gestión de la calidad de los servicios y de la evaluación de políticas públicas.

\section{País Vasco}

En el proyecto de ley de transparencia, participación ciudadana y buen gobierno de la Comunidad Autónoma del País Vasco la evaluación de políticas públicas ocupa un lugar destacado y es una constante a lo largo de todo el texto. Se detallan numerosos aspectos del proceso de evaluación y expresamente mandata la publicación tanto de los procesos evaluativos como de los resultados.

Somete a publicidad activa la evaluación que resulta obligada realizar de los planes y programas anuales y plurianuales del conjunto de las entidades que componen el sector público de la Comunidad Autónoma de Euskadi. Pero no se queda ahí y dedica todo un Título (Título II) al «Fomento de la planificación y evaluación de políticas públicas y publicidad de estos procesos» para el que el propio proyecto fija un calendario de aplicación específico.

Distingue varios tipos de evaluación. En primer lugar, se refiere a la evaluación previa de impacto de proyectos de ley, de planes estratégicos y de actuaciones significativas ${ }^{23}$, que define como un

23 Evaluación previa de impacto que va más allá que la evaluación previa de impacto regulatorio, que tiene como objeto el análisis ex ante de las políticas públicas recogida en propuesta normativas. 
«...proceso sistemático de observación, medida, análisis e interpretación de información obtenida de forma exhaustiva y ordenada, encaminado a la estimación cualitativa y, siempre que sea posible, cuantitativa, de los costes y beneficios económicos, sociales y medioambientales probables de las distintas opciones de política pública para alcanzar un juicio propositivo o valorativo basado en evidencias, respecto de su diseño, puesta en práctica e impacto, que informe la decisión a adoptar por el órgano competente».

La evaluación así considerada se proyecta, primero, sobre un Plan de Gobierno Abierto, que se debe elaborar en cada legislatura y de contenido abierto. Este Plan debe identificar proyectos de ley, planes estratégicos y actuaciones significativas e incluir, entre otros contenidos, los indicadores que permitan su seguimiento y evaluación.

Junto al Plan de Gobierno, también dispone que el Gobierno Vasco determine anualmente una relación de intervenciones públicas que, como mínimo, deberán ser evaluadas, atendiendo a una serie de criterios. Y además, los departamentos o entes del sector público vasco podrán someter a evaluación aquellas otras intervenciones públicas de su competencia que estimen conveniente.

En segundo lugar, define la evaluación de resultados e impactos acumulados de las políticas públicas:

«... aquélla que se efectúa con posterioridad a la ejecución de la política pública y que se fija en el examen de su pertinencia, eficacia, eficiencia, impacto y sostenibilidad a la luz de los objetivos que se planificaron».

Este proyecto de ley reconoce el derecho de los ciudadanos a participar en la evaluación de programas y políticas públicas; participación ciudadana que es objeto de regulación en un título específico (Título IV), en el que se contempla la evaluación del grado de participación ciudadana, de los medios empleados y su resultado, con el fin de adoptar cuantas medidas fueran necesarias para implementar procesos de mejora.

\section{Comunidad Valenciana}

Este subgrupo se cierra con la Comunidad Valenciana que en su Ley 2/2015, de 2 de abril, de transparencia, buen gobierno y participación ciudadana, y al igual que anteriores CC.AA, vincula la evaluación de políticas públicas a la transparencia, a través de la participación ciudadana y fija las bases para la evaluación de la acción de gobierno.

Como la mayoría de las normas de transparencia, somete a publicidad activa las evaluaciones que se realicen sobre el grado de cumplimiento y resultados de los planes y programas anuales y plurianuales, y extiende esta obligación de publicidad a los "informes de evaluación de las políticas públicas y de calidad de los servicios públicos".

En este ámbito de evaluación de políticas públicas, da un paso más al recoger la previsión de que sea una entidad experta e independiente la que evalúe de forma objetiva y periódica las políticas públicas llevadas a cabo por la Generalitat en el ámbito de aplicación de la ley (disposición adicional séptima).

Dedica un título (Título V) a la participación ciudadana y encarga a la Generalitat que impulse la implicación ciudadana en la formulación y evaluación de las políticas públicas. Mediante Decreto 190/2016, de 16 de diciembre, por el que desarrolla el Consejo de Participación Ciudadana, atribuye a este órgano consultivo de la Administración de la Generalitat la función de evaluar la ejecución de políticas que se desarrollen en materia de participación ciudadana y fomento del asociacionismo.

También en desarrollo de su ley de trasparencia, esta Comunidad Autónoma ha aprobado el Decreto 41/2016, de 15 de abril, del Consell, por el que se establece el sistema para la mejora de la calidad de los servicios públicos y la evaluación de los planes y programas en la Administración de la Generalitat y su sector público instrumental.

Con esta disposición se unifica en un solo texto los instrumentos de mejora de la calidad de los servicios y la evaluación, que centra casi en exclusiva en los planes y programas, con especial hincapié en la evaluación de resultados. A tal efecto, en su art.12 incide en la evaluación del grado de cumplimiento y resultados de los planes y programas, «... sin perjuicio de las variadas técnicas y herramientas de medición y evaluación de la actividad o intervención pública que en cada caso puedan desarrollarse desde diferentes puntos de vista...». Define la evaluación de calidad, pero no la evaluación de planes y programas. 


\subsubsection{Dentro de este mismo apartado, el segundo grupo lo forman aquellas CC.AA con desarrollos específicos en materia de evaluación de políticas públicas, con independencia de las posibles referencias que, al respecto, pueda contener su normativa de transparencia: Castilla y León, Cataluña, Región de Murcia y Navarra.}

Castilla y León

La Comunidad Autónoma de Castilla y León, en su Ley 3/2015, de 4 de marzo, de transparencia y participación ciudadana, se remite expresamente a la información que se ha de publicar en cumplimiento de la LTAIBG (normativa básica).

Pero esta CA cuenta con una regulación específica: la Ley 2/2010, de 11 de marzo, de Derechos de los Ciudadanos en sus relaciones con la Administración de la Comunidad de Castilla y León y de Gestión Pública. Es en esta norma donde desarrolla la evaluación de las políticas públicas, que constituye uno de sus objetos. Obliga a la Administración autonómica a impulsar la cultura de la evaluación de la acción pública y dispone que

"La evaluación será integral y objetiva, y sus resultados, conclusiones y áreas de mejora serán públicos».

Prevé la posibilidad de externalizar el proceso evaluativo, regula el contenido de las evaluaciones y su realización en fase de diseño, implementación o resultados.

Asimismo, reconoce el derecho de los ciudadanos de Castilla y León a participar en la elaboración, aplicación y evaluación de las políticas públicas de la Administración autonómica. Sin embargo, tal reconocimiento parece necesitar de un posterior desarrollo reglamentario.

\section{Cataluña}

La Comunidad Autónoma de Cataluña destaca sin duda sobre las demás comunidades autónomas, al contar con una amplia y consolidada trayectoria en materia de evaluación de políticas públicas, que encuentra institucionalizada a través del Instituto Catalán de Evaluación de Políticas Públicas (Ivàlua), consorcio público constituido formalmente en $2006^{24}$ y con inicio de actividad en 2008. Una de las finalidades de este consorcio es evaluar políticas públicas por encargo de las administraciones públicas y de las entidades sin ánimo de lucro, así como la de difundir sus resultados, "... mediante formatos y canales adaptados a los diferentes tipos de destinatarios».

Quizás sea esta la razón por la cual su Ley 19/2014, de 29 de diciembre, de transparencia, acceso a la información pública y buen gobierno, no incide más en la evaluación, a la que dedica referencias muy puntuales.

En concreto, se encuentran dos menciones en la parte que regula la publicidad activa. La primera de ellas, referida a la información sobre organización institucional y estructura administrativa, cuando señala que será público el catálogo de los servicios prestados, las cartas de servicios existentes ${ }^{25}$ " ... y la información sobre los resultados de las evaluaciones de calidad y de la incidencia social de las políticas públicas» ${ }^{26}$. La segunda referencia aparece en el precepto que regula la publicidad activa de la información sobre planificación y programación: siguiendo la normativa básica, establece que la Administración debe hacer públicos, en aplicación del principio de transparencia, los planes y programas anuales y plurianuales, de carácter general o sectorial, que establecen las directrices estratégicas de las políticas públicas, incluyendo los criterios y la metodología para evaluar su cumplimiento y el resultado de la evaluación, una vez ejecutados.

También es sucinta la parte que dedica a la participación y colaboración ciudadanas en la toma de decisiones públicas y en el seguimiento y la evaluación de la aplicación de dichas decisiones, en el título en el que aborda el gobierno abierto, ya que también dispone de normativa específica sobre participación

24 El Acuerdo de creación de Iválua, Acuerdo de Gobierno de 11 de julio de 2006, ha sido objeto de varias modificaciones. La última de ellas, a través del Acuerdo de Gobierno 115/2015, de 21 de julio, por el que se autoriza la modificación de sus estatutos y se aprueba su texto íntegro

25 Es tal el compromiso que esta CA adquiere con la ciudadanía, que la ley atribuye naturaleza reglamentaria a las cartas de servicios. En consecuencia, su contenido es vinculante y puede ser invocado por vía de recurso o reclamación (art. 59.2 Ley 19/2014).

26 Esta misma expresión («incidencia social») es utilizada en las normativas de la CC.AA de Cantabria y Navarra. 
ciudadana, a la que se remite. Se trata de la Ley 10/2014, de 26 de septiembre, de consultas populares no referendarias y otras formas de participación ciudadana. Participación ciudadana que desarrolla en su Título III y extiende a las actuaciones públicas en las fases de propuesta, decisión, aplicación o evaluación. Dispone su evaluación y destina un precepto (artículo 50) a recoger todos y cada uno de los extremos que debe contener la memoria resultante de la obligada evaluación de los procesos de participación.

\section{Región de Murcia}

La Comunidad Autónoma de la Región de Murcia cuenta, por un lado, con su Ley 12/2014, de 16 de diciembre, de transparencia y participación ciudadana, que ha sido objeto de reciente modificación ${ }^{27}$, con la intención, según se recoge en su preámbulo, de reforzar la regulación anterior en el sentido de garantizar de forma más efectiva la transparencia, el derecho de acceso a la información pública, el derecho a la participación ciudadana en la toma de decisiones y la evaluación de políticas públicas. Sin embargo, tal declaración sobre la evaluación de políticas públicas no se ha plasmado en la parte dispositiva del texto.

De hecho, presenta una peculiaridad respecto de las restantes CC.AA, ya que cuando sujeta a publicidad activa la información sobre el grado de cumplimiento y los resultados de los planes y programas anuales y plurianuales que aprueben, omite el término «evaluación». Tal omisión no impide se incluya en este grupo por dos motivos: primero, porque son múltiples las referencias a la evaluación de políticas públicas, sin bien en todo caso vinculadas a la participación ciudadana, a la que dedica un título (Título III) en el que reconoce el derecho de los ciudadanos a participar en la planificación, seguimiento y la evaluación de los programas y políticas públicas. Esta disposición recoge expresamente la evaluación tanto de las políticas de participación ciudadana como de sus instrumentos.

El segundo motivo que avala su inclusión en este grupo es que esta Comunidad Autónoma cuenta con otra norma: la Ley 2/2014, de 21 de marzo, de Proyectos Estratégicos, Simplificación Administrativa y Evaluación de los Servicios Públicos de la CARM que, persigue, entre otros fines, impulsar la cultura de evaluación en la gestión pública regional, mediante sistemas de evaluación de los resultados e impacto de las políticas públicas. Se refiere a sistemas de evaluación de las políticas públicas y concibe la evaluación como una actividad específica y con identidad propia, claramente diferenciada de otras como el control interno, la auditoría financiera, la auditoría de gestión o el control presupuestario, pero con las que mantiene una estrecha relación de complementariedad. En tal sentido, considera la evaluación de las políticas públicas como

«... el proceso integral de análisis de su conceptualización y diseño, de su proceso de ejecución, aplicación y seguimiento, así como de la valoración de los resultados e impactos conseguidos mediante dichas políticas».

Sin embargo, no recoge expresamente a la publicidad de las evaluaciones que se realicen.

\section{Navarra}

Este grupo se cierra con la Comunidad Foral de Navarra que, en su normativa reguladora de la transparencia -Ley Foral 11/2012, de 28 de junio, de transparencia y gobierno abierto (modificada por Ley 5/2016, de 28 de abril)- sujeta a publicidad activa, al igual que Cantabria y Cataluña, la información sobre el resultado de las «... evaluaciones de la calidad de los servicios públicos, así como de la incidencia social de las políticas públicas». También dispone la publicidad de la información sobre los programas anuales y plurianuales que vaya a acometer; pero su evaluación la reserva para el título dedicado al diseño de un marco general para la mejora continua de la calidad de la Administración (Título VI), cuando menciona la "... evaluación permanente de los servicios, programas, planes y políticas públicas» como una de las estrategias de calidad.

Regula pormenorizadamente a la participación ciudadana (Título IV), y reconoce el derecho de los ciudadanos a colaborar y participar en la evaluación de las políticas públicas y la calidad de los servicios de la Administración Pública. Los resultados de la participación se plasmarán en un informe de participación y colaboración, pero no prescribe su evaluación. Por lo demás, en materia de participación, se remite a la nor-

27 Mediante Ley 7/2016, de 8 de mayo, de reforma de la Ley 12/2014, de 16 de diciembre, de transparencia y participación ciudadana de la Comunidad Autónoma de la Región de Murcia. 
mativa foral reguladora de la evaluación de las políticas públicas: la Ley Foral 21/2005, de 29 de diciembre, de evaluación de las políticas públicas y de la calidad de los servicios públicos.

Esta disposición no contiene una definición de evaluación de políticas públicas, pero sí sus modalidades, finalidad y momento de su realización, los contenidos y la obligación de su publicidad

"Las Administraciones Públicas darán a sus evaluaciones, que serán públicas, la publicidad que juzguen oportuno y por los medios técnicos que consideren más adecuados».

Crea la Comisión Foral para la Evaluación de las Políticas Públicas y la Calidad de los Servicios Públicos (CFE), como órgano colegiado de la Administración de la Comunidad Foral de Navarra centrado en actividades de formación, sensibilización y promoción de la evaluación, además de actuar como registro de las evaluaciones que realice el gobierno foral.

- El respaldo otorgado a la evaluación de políticas públicas y su publicidad por la disposiciones autonómicas de transparencia ha venido a completar y fortalecer los reconocimientos normativos con los que ya contaba en algunas comunidades autónomas.

- Es importante destacar que 6 de las 17 normas autonómicas en materia de transparencia (aprobadas o en fase de proyecto) recogen una definición muy precisa de la evaluación, marcando la diferencia con otros instrumentos de información y valoración de los que se puedan servir los decisores políticos.

- Dotar a la evaluación de políticas públicas y su publicidad de un marco legal constituye un refuerzo indiscutible al sentar los cimientos que pueden ayudar a su desarrollo y garantizar la consolidación de su práctica que dependerá, en todo caso, de la voluntad política.

- No obstante lo incipiente de marco legal, sean bienvenidas las numerosas referencias a la evaluación de las intervenciones públicas y su publicidad, que deben ser valoradas muy positivamente. El impulso es evidente, al igual que su vinculación a la transparencia y la rendición de cuentas: evaluación de políticas públicas y difusión como medidas indispensables de transparencia y rendición de cuentas.

El cuadro que figura a continuación pretende sintetizar lo expuesto hasta el momento, recogiendo el reconocimiento normativo de la evaluación en el panorama autonómico, bien a través de las leyes de transparencia -aprobadas o en proyecto-, bien a través de otros textos normativos en vigor que las complementan.

CUADRO 2. RESPALDO NORMATIVO AUTONÓMICO A LA EVALUACIÓN

\begin{tabular}{|c|c|c|c|c|c|c|c|}
\hline $\begin{array}{l}\text { COMUNIDAD } \\
\text { AUTÓNOMA }\end{array}$ & 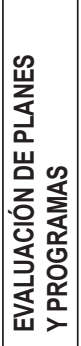 & 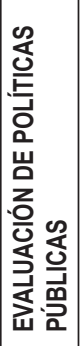 & 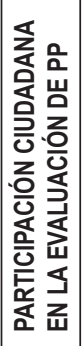 & 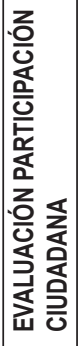 & $\begin{array}{l}\text { OTROS CONTENIDOS } \\
\text { RELACIONADOS }\end{array}$ & $\begin{array}{c}\text { NORMATIVA DE } \\
\text { TRANSPARENCIA } \\
\text { (en vigor o en proyecto) }\end{array}$ & $\begin{array}{l}\text { DISPOSICIONES } \\
\text { RELACIONADAS } \\
\text { (en vigor) }\end{array}$ \\
\hline ANDALUCIA & $\mathrm{x}$ & & & & $\begin{array}{l}\text { Define «evaluación de } \\
\text { políticas públicas». Su } \\
\text { Estatuto de Autonomía } \\
\text { recoge una previsión de } \\
\text { desarrollo mediante ley }\end{array}$ & $\begin{array}{l}\text { Ley } 1 / 2014 \text {, de } 24 \text { de junio, } \\
\text { de transparencia pública de } \\
\text { Andalucía }\end{array}$ & \\
\hline ARAGÓN & $x$ & & $\mathrm{x}$ & $x$ & $\begin{array}{l}\text { Define «evaluación». } \\
\text { Dispone la evaluación del } \\
\text { Plan de Gobierno }\end{array}$ & $\begin{array}{l}\text { Ley } 8 / 2015 \text {, de } 25 \text { de } \\
\text { marzo, de transparencia } \\
\text { de la actividad pública y } \\
\text { participación ciudadana de } \\
\text { Aragón }\end{array}$ & \\
\hline $\begin{array}{l}\text { PRINCIPADO } \\
\text { DE ASTURIAS }\end{array}$ & $x$ & $\mathrm{X}$ & $x$ & & Define «evaluación» & $\begin{array}{l}\text { Proyecto de ley del } \\
\text { Principado de Asturias de } \\
\text { transparencia }\end{array}$ & \\
\hline
\end{tabular}




\begin{tabular}{|c|c|c|c|c|c|c|c|}
\hline $\begin{array}{l}\text { COMUNIDAD } \\
\text { AUTÓNOMA }\end{array}$ & 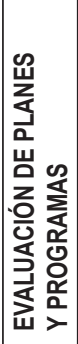 & 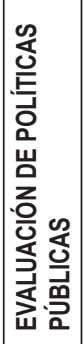 & 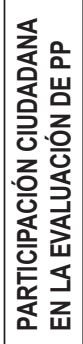 & 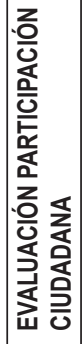 & $\begin{array}{l}\text { OTROS CONTENIDOS } \\
\text { RELACIONADOS }\end{array}$ & $\begin{array}{c}\text { NORMATIVA DE } \\
\text { TRANSPARENCIA } \\
\text { (en vigor o en proyecto) }\end{array}$ & $\begin{array}{l}\text { DISPOSICIONES } \\
\text { RELACIONADAS } \\
\text { (en vigor) }\end{array}$ \\
\hline ILLES BALEARS & $x$ & $x$ & $x$ & & $\begin{array}{l}\text { Define «evaluación». Crea } \\
\text { la Oficina de Evaluación } \\
\text { Pública de las Illes Balears, } \\
\text { como órgano de ejecución, } \\
\text { coordinación y consulta de } \\
\text { las acciones evaluaciones }\end{array}$ & $\begin{array}{l}\text { Ley } 4 / 2011 \text {, de } 31 \text { de marzo, } \\
\text { de buena administración } \\
\text { y de buen gobierno de las } \\
\text { Illes Balears }\end{array}$ & \\
\hline CANARIAS & $x$ & & $\mathrm{X}$ & $x$ & & $\begin{array}{l}\text { Ley } 5 / 2010 \text {, de } 21 \text { de junio, } \\
\text { canaria de fomento de la } \\
\text { participación ciudadana }\end{array}$ & $\begin{array}{l}\text { Ley } 12 / 2014 \text {, de } 26 \text { de } \\
\text { diciembre, de transparencia } \\
\text { y de acceso a la } \\
\text { información pública }\end{array}$ \\
\hline CANTABRIA & $\mathrm{x}$ & & $\mathrm{X}$ & $\mathrm{X}$ & $\begin{array}{l}\text { Define «evaluación». } \\
\text { Dispone la publicidad de las } \\
\text { «evaluaciones de calidad } \\
\text { y de la incidencia social de } \\
\text { las políticas públicas» }\end{array}$ & $\begin{array}{l}\text { Proyecto de Ley de } \\
\text { transparencia de la } \\
\text { actividad pública y } \\
\text { participación ciudadana de } \\
\text { Cantabria }\end{array}$ & \\
\hline $\begin{array}{l}\text { CASTILLA-LA } \\
\text { MANCHA }\end{array}$ & $\mathrm{x}$ & & $x$ & $\mathrm{X}$ & Define «evaluación» & $\begin{array}{l}\text { Ley } 4 / 2016 \text {, de } 15 \text { de } \\
\text { diciembre, de transparencia } \\
\text { y buen gobierno de Castilla- } \\
\text { La Mancha }\end{array}$ & \\
\hline $\begin{array}{l}\text { CASTILLA Y } \\
\text { LEÓN }\end{array}$ & $x$ & $X$ & $\mathrm{X}$ & & & $\begin{array}{l}\text { Ley } 2 / 2010 \text {, de } 11 \text { de } \\
\text { marzo, de derechos } \\
\text { de los ciudadanos en } \\
\text { sus relaciones con la } \\
\text { Administración de la } \\
\text { Comunidad de Castilla y } \\
\text { León y de gestión pública }\end{array}$ & $\begin{array}{l}\text { Ley } 3 / 2015 \text {, de } 4 \text { de } \\
\text { marzo, de transparencia y } \\
\text { participación ciudadana de } \\
\text { Castilla y León }\end{array}$ \\
\hline CATALUÑA & $x$ & $x$ & $x$ & $x$ & $\begin{array}{l}\text { IVÁLUA evalúa políticas } \\
\text { públicas y difunde sus } \\
\text { resultados. Dispone } \\
\text { la publicidad de las } \\
\text { «evaluaciones de calidad } \\
\text { y de la incidencia social de } \\
\text { las políticas públicas» }\end{array}$ & $\begin{array}{l}\text { Ley } 19 / 2014 \text {, de } 29 \text { de } \\
\text { diciembre, de transparencia, } \\
\text { acceso a la información } \\
\text { pública y buen gobierno }\end{array}$ & $\begin{array}{l}\text { Acuerdo de Gobierno de } \\
11 \text { julio } 2006 \text { (IVÁLUA) } \\
\text { y Ley } 10 / 2014, \text { de } 26 \text { de } \\
\text { septiembre, de consultas } \\
\text { populares no referendarias } \\
\text { y otras formas de } \\
\text { participación ciudadana }\end{array}$ \\
\hline EXTREMADURA & $x$ & & $\mathrm{x}$ & & & $\begin{array}{l}\text { Ley } 4 / 2013 \text {, de } 21 \text { de mayo, } \\
\text { de gobierno abierto de } \\
\text { Extremadura }\end{array}$ & \\
\hline GALICIA & $x$ & & & & $\begin{array}{l}\text { Se refiere a «evaluaciones } \\
\text { de calidad de las polticas } \\
\text { públicas y de los servicos } \\
\text { públicos» }\end{array}$ & $\begin{array}{l}\text { Ley } 1 / 2016, \text { de } 28 \text { de enero, } \\
\text { de transparencia y buen } \\
\text { gobierno }\end{array}$ & $\begin{array}{l}\text { Ley } 1 / 2015 \text {, de } 1 \text { de abril, } \\
\text { de garantía de la calidad } \\
\text { de los servicios públicos y } \\
\text { de la buena administración }\end{array}$ \\
\hline LA RIOJA & $x$ & & & & & $\begin{array}{l}\text { Ley } 3 / 2014 \text {, de } 11 \\
\text { de septiembre, de } \\
\text { transparencia y buen } \\
\text { gobierno de La Rioja }\end{array}$ & \\
\hline MADRID & $x$ & & $\mathrm{X}$ & & $\begin{array}{l}\text { Dispone la evaluación del } \\
\text { Plan de Gobierno }\end{array}$ & $\begin{array}{l}\text { Proyecto de Ley de } \\
\text { Gobierno Abierto, } \\
\text { participación ciudadana } \\
\text { y transparencia de la } \\
\text { Comunidad de Madrid }\end{array}$ & \\
\hline
\end{tabular}




\begin{tabular}{|c|c|c|c|c|c|c|c|}
\hline $\begin{array}{l}\text { COMUNIDAD } \\
\text { AUTÓNOMA }\end{array}$ & 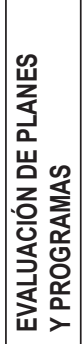 & 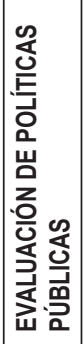 & 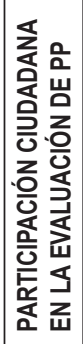 & 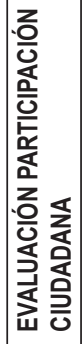 & $\begin{array}{l}\text { OTROS CONTENIDOS } \\
\text { RELACIONADOS }\end{array}$ & $\begin{array}{c}\text { NORMATIVA DE } \\
\text { TRANSPARENCIA } \\
\text { (en vigor o en proyecto) }\end{array}$ & $\begin{array}{l}\text { DISPOSICIONES } \\
\text { RELACIONADAS } \\
\text { (en vigor) }\end{array}$ \\
\hline $\begin{array}{l}\text { REGIÓN DE } \\
\text { MURCIA }\end{array}$ & & $x$ & $x$ & $x$ & & $\begin{array}{l}\text { Ley } 12 / 2014 \text {, de } 16 \text { de } \\
\text { diciembre, de transparencia } \\
\text { y participación ciudadana } \\
\text { de la Comunidad Autónoma } \\
\text { de la Región de Murcia }\end{array}$ & $\begin{array}{l}\text { Ley } 2 / 2014 \text {, de } 21 \text { de } \\
\text { marzo, de proyectos } \\
\text { estratégicos, simplificación } \\
\text { administrativa y evaluación } \\
\text { de los servicios públicos de } \\
\text { la CARM }\end{array}$ \\
\hline NAVARRA & $x$ & $x$ & $x$ & & $\begin{array}{l}\text { Publicidad de las } \\
\text { «evaluaciones de calidad } \\
\text { y de la incidencia social } \\
\text { de las políticas públicas». } \\
\text { Comisión Foral para la } \\
\text { Evaluación de las Políticas } \\
\text { Públicas y la Calidad de } \\
\text { los Servicios Públicos con } \\
\text { funciones de formación, } \\
\text { sensibilización y promoción, } \\
\text { además de registro }\end{array}$ & $\begin{array}{l}\text { Ley Foral } 11 / 2012 \text {, de } 21 \text { de } \\
\text { junio, de la transparencia y } \\
\text { del gobierno abierto }\end{array}$ & $\begin{array}{l}\text { Ley Foral } 21 / 2005 \text {, de } 29 \text { de } \\
\text { diciembre, de evaluación de } \\
\text { las políticas públicas y de } \\
\text { la calidad de los servicios } \\
\text { públicos }\end{array}$ \\
\hline PAÍS VASCO & $x$ & $x$ & $x$ & $x$ & $\begin{array}{l}\text { Define «evaluación». } \\
\text { Dispone la evaluación del } \\
\text { Plan de Gobierno }\end{array}$ & $\begin{array}{l}\text { Proyecto de Ley de } \\
\text { transparencia, participación } \\
\text { ciudadana y buen gobierno } \\
\text { del sector público vasco }\end{array}$ & \\
\hline $\begin{array}{l}\text { COMUNIDAD } \\
\text { VALENCIANA }\end{array}$ & $x$ & $X$ & $x$ & $x$ & $\begin{array}{l}\text { Prevé la creación de } \\
\text { una entidad experta e } \\
\text { independiente la que } \\
\text { evalúe de forma objetiva } \\
\text { y periódica las políticas } \\
\text { públicas }\end{array}$ & $\begin{array}{l}\text { Ley } 2 / 2015 \text {, de } 2 \text { de abril, } \\
\text { de transparencia, buen } \\
\text { gobierno y participación } \\
\text { ciudadana y desarrollos }\end{array}$ & \\
\hline
\end{tabular}

Fuente: elaboración propia a partir de la normativa de transparencia (aprobada o en fase de proyecto -en cursiva-) y demás normativa autonómica en vigor relacionada con la evaluación.

\section{ANEXO. NORMATIVA ANALIZADA}

ESTATAL Real Decreto 799/2005, de 1 de julio, por el que se regulan las inspecciones generales de los departamentos ministeriales

Ley 19/2013, de 9 de diciembre, de transparencia, acceso a la información pública y buen gobierno

Ley 39/2015, de 1 de octubre, del procedimiento administrativo común de las administraciones públicas

Ley 40/2015, de 1 de octubre, de régimen jurídico del sector público

\begin{tabular}{ll}
\hline ANDALUCÍA & Ley $1 / 2014$, de 24 de junio, de transparencia pública de Andalucía \\
\hline ARAGÓN & $\begin{array}{l}\text { Ley } 8 / 2015, \text { de } 25 \text { de marzo, de transparencia de la actividad pública y participación } \\
\text { ciudadana de Aragón }\end{array}$ \\
\hline
\end{tabular}

PRINCIPADO DE Proyecto de ley del Principado de Asturias de transparencia ASTURIAS 


\begin{tabular}{|c|c|}
\hline ILLES BALEARS & $\begin{array}{l}\text { Ley } 4 / 2011 \text {, de } 31 \text { de marzo, de buena administración y de buen gobierno } \\
\text { de las Illes Balears }\end{array}$ \\
\hline \multirow[t]{2}{*}{ CANARIAS } & Ley $5 / 2010$, de 21 de junio, canaria de fomento de la participación ciudadana \\
\hline & $\begin{array}{l}\text { Ley } 12 / 2014 \text {, de } 26 \text { de diciembre, de transparencia y de acceso a la información } \\
\text { pública }\end{array}$ \\
\hline CANTABRIA & $\begin{array}{l}\text { Proyecto de Ley de transparencia de la actividad pública y participación ciudadana } \\
\text { de Cantabria }\end{array}$ \\
\hline CASTILLA-LA MANCHA & $\begin{array}{l}\text { Ley } 4 / 2016 \text {, de } 15 \text { de diciembre, de transparencia y buen gobierno } \\
\text { de Castilla-La Mancha }\end{array}$ \\
\hline \multirow[t]{2}{*}{ CASTILLA Y LEÓN } & $\begin{array}{l}\text { Ley } 2 / 2010 \text {, de } 11 \text { de marzo, de derechos de los ciudadanos en sus relaciones } \\
\text { con la Administración de la Comunidad de Castilla y León y de gestión pública }\end{array}$ \\
\hline & $\begin{array}{l}\text { Ley } 3 / 2015 \text {, de } 4 \text { de marzo, de transparencia y participación ciudadana } \\
\text { de Castilla y León }\end{array}$ \\
\hline \multirow[t]{3}{*}{ CATALUÑA } & $\begin{array}{l}\text { Acuerdo de Gobierno de } 11 \text { de julio de } 2006 \text {, por el que se autoriza la constitución del } \\
\text { Consorcio titular del Instituto Catalán de Evaluación de Políticas Públicas } \\
\text { (última modificación por Acuerdo de Gobierno 115/2015, de } 21 \text { de julio) }\end{array}$ \\
\hline & $\begin{array}{l}\text { Ley } 10 / 2014 \text {, de } 26 \text { de septiembre, de consultas populares no referendarias y otras } \\
\text { formas de participación ciudadana }\end{array}$ \\
\hline & $\begin{array}{l}\text { Ley } 19 / 2014 \text {, de } 29 \text { de diciembre, de transparencia, acceso a la información pública } \\
\text { y buen gobierno }\end{array}$ \\
\hline EXTREMADURA & Ley $4 / 2013$, de 21 de mayo, de gobierno abierto de Extremadura \\
\hline \multirow[t]{2}{*}{ GALICIA } & $\begin{array}{l}\text { Ley } 1 / 2015 \text {, de } 1 \text { de abril, de garantía de la calidad de los servicios públicos } \\
\text { y de la buena administración }\end{array}$ \\
\hline & Ley $1 / 2016$, de 28 de enero, de transparencia y buen gobierno \\
\hline LA RIOJA & Ley $3 / 2014$, de 11 de septiembre, de transparencia y buen gobierno de La Rioja \\
\hline MADRID & $\begin{array}{l}\text { Proyecto de Ley de Gobierno Abierto, participación ciudadana y transparencia } \\
\text { de la Comunidad de Madrid }\end{array}$ \\
\hline \multirow[t]{2}{*}{ REGIÓN DE MURCIA } & $\begin{array}{l}\text { Ley } 2 / 2014 \text {, de } 21 \text { de marzo, de proyectos estratégicos, simplificación administrativa } \\
\text { y evaluación de los servicios públicos de la CARM, }\end{array}$ \\
\hline & $\begin{array}{l}\text { Ley } 12 / 2014 \text {, de } 16 \text { de diciembre, de transparencia y participación ciudadana } \\
\text { de la Comunidad Autónoma de la Región de Murcia (modificada por Ley } 7 / 2016 \text {, } \\
\text { de } 8 \text { de mayo) }\end{array}$ \\
\hline \multirow[t]{2}{*}{ NAVARRA } & $\begin{array}{l}\text { Ley Foral } 21 / 2005 \text {, de } 29 \text { de diciembre, de evaluación de las políticas públicas } \\
\text { y de la calidad de los servicios públicos. }\end{array}$ \\
\hline & $\begin{array}{l}\text { Ley Foral } 11 / 2012 \text {, de } 21 \text { de junio, de la transparencia y del gobierno abierto } \\
\text { (modificada por Ley } 5 / 2016 \text {, de } 28 \text { de abril) }\end{array}$ \\
\hline PAÍS VASCO & $\begin{array}{l}\text { Proyecto de Ley de transparencia, participación ciudadana y buen gobierno } \\
\text { del sector público vasco }\end{array}$ \\
\hline \multirow{3}{*}{$\begin{array}{l}\text { COMUNIDAD } \\
\text { VALENCIANA }\end{array}$} & Ley $2 / 2015$, de 2 de abril, de transparencia, buen gobierno y participación ciudadana \\
\hline & $\begin{array}{l}\text { Decreto } 41 / 2016 \text {, de } 15 \text { de abril, del Consell, por el que se establece el sistema } \\
\text { para la mejora de la calidad de los servicios públicos y la evaluación de los planes } \\
\text { y programas en la Administración de la Generalitat y su sector público instrumental }\end{array}$ \\
\hline & $\begin{array}{l}\text { Decreto 190/2016, de } 16 \text { de diciembre, del Consell, por el que se regula el Consejo } \\
\text { de Participación Ciudadana de la Comunitat Valenciana }\end{array}$ \\
\hline
\end{tabular}




\section{BIBLIOGRAFÍA}

AEVAL (2015): "Guía práctica para el diseño y la realización de evaluaciones de políticas públicas. Enfoque AEVAL". Madrid. En línea: http://www.aeval.es/es/difusion_y_comunicacion/publicaciones/Guias/Guias_Evaluacion_ Politicas_Publicas_y_Calidad_SSPP/Guia_evaluaciones_AEVAL.html (consulta: 8 de marzo de 2017).

AEVAL (2010): "Fundamentos de evaluación de políticas públicas". Madrid. En línea: http://www.aeval.es/es/difusion y comunicacion/publicaciones/Guias/Guias_Evaluacion_Politicas_Publicas_y_Calidad_SSPP/Fundamentos evaluacion.html (consulta: 8 de marzo de 2017).

AEVAL (2009): "La función evaluadora: principios orientadores y directrices de actuación en la evaluación de políticas públicas". Madrid. En línea: http://www.aeval.es/export/sites/aeval/comun/pdf/actualidad/Funcion_evaluadora.pdf (consulta: 8 de marzo de 2017).

INAP. OCDE (2016): Panorama de las Administraciones Públicas 2015. Madrid.

CTBG (2016) "Memoria anual 2015". Madrid. En línea: http://www.consejodetransparencia.es/ct_Home/plan_memoria/ memorias.html (consulta: 8 de febrero de 2017).

TAMAYO SÁEZ, Manuel (1997): "El análisis de las políticas públicas”, en BAÑON, Rafael y Ernesto CARRILLO (comps.) La nueva administración pública. Madrid, Alianza. 